\title{
Geographic distribution indices of general practitioners, midwives, pediatricians, and gynecologists in the public sector of Iran
}

\author{
Rasoul Honarmand ${ }^{1}$, Mostafa Mozhdehifard ${ }^{2}$, Zahra Kavosi $^{3,4}$
}

${ }^{1}$ M.Sc. of Health Management, Health Human Resources Research Center, School of Management \& Information Sciences, Shiraz University of Medical Sciences, Shiraz, Iran

${ }^{2}$ DDS. Health Management and Economics Research Center, Iran University of Medical Sciences, Tehran, Iran

${ }^{3}$ Ph.D. of Health Management, Associate Professor, Health Policy Research Center, Shiraz University of Medical Sciences, Shiraz, Iran

${ }^{4} \mathrm{Ph} . \mathrm{D}$. of Health Management, Associate Professor, Health Human Resources Research Center, School of Management \& Information Sciences, Shiraz University of Medical Sciences, Shiraz, Iran

\section{Type of article: Original}

\begin{abstract}
Background: Health workforce distribution is so important in access posture, coverage and equity. Following millennium development goals (MDGs), special attention to health workforces in relation with maternal and child health is required.

Objective: The aim of the current study was to determine distribution of maternal and child health related workforces in Iran during 2010-2012, using inequality measures.

Methods: In this cross-sectional study, data about the number of physicians and midwives obtained from Ministry of Health reports and demographic statistics were obtained from the Statistical Center of Iran. Gini coefficient and Robin Hood index were calculated in terms of population ratio, need adjusted index for birth (NAIB) and need adjusted index for mortality (NAIM). For calculations, DAD software version 4.6 was used.

Results: Gini coefficient was reduced for general physicians (GPs) and pediatricians, and had increasing and decreasing trends for gynecologists. For achieving equality within provinces, the number of transferable health workforces was more than 1 person per 10 health workforces.

Conclusion: Health workforce distribution had various trends in Iran. Special attention to deprived provinces is required. Most of the reduction in Gini coefficient is due to the increase in health workforce in developing provinces, and deprived provinces still have serious problems. The health system could achieve better equality by considering deprived provinces and using Gini coefficient and Robin Hood index together.
\end{abstract}

Keywords: Equality, Human Resource, Gini coefficient, Robin Hood index, Maternal Health

\section{Introduction}

Health systems are extremely dependent on human resources in order to provide high quality services (1). For delivering health care, particularly in developing countries, the lack of qualified human resources and unequal distribution of health workforces is a main problem (2-4). Furthermore, health workforce distribution is very important in access posture, coverage and equity (5). Growth in inequalities, access problems and costs, forced many countries to improve their policies; especially human resource distributing policies with these facts (6). However, ideal health outcomes are directly dependent on the distribution of the health workforces (6), and evidence shows there are tight relationships between number and quality of health workforces and primary health care services, vaccination coverage and maternal mortality rate $(7,8)$. Often, there are many inequalities in the distribution of healthcare personnel within countries and between regions and provinces of a country (9-11). It is a

\section{Corresponding author:}

Associate Professor Dr. Zahra Kavosi, Health Human Resources Research Center, School of Management \& Information Sciences, Shiraz University of Medical Sciences, Shiraz, Iran.

Tel: +98.9177284865, Email: zhr.kavosi@gmail.com

Received: November 11, 2016, Accepted: March 18, 2017, Published: June 2017

iThenticate screening: February 13, 2017, English editing: April 12, 2017, Quality control: May 14, 2017

(C) 2017 The Authors. This is an open access article under the terms of the Creative Commons Attribution-NonCommercialNoDerivs License, which permits use and distribution in any medium, provided the original work is properly cited, the use is non-commercial and no modifications or adaptations are made. 
considerable problem in developing countries that health-related workforce is condensed in big towns and cities, and rural regions are allocated only $23 \%$ and $38 \%$ of the country's general practitioners and nurses, and these inequities resist against the changes (12). This problem involved developed countries such as the UK, America, Japan, Australia, Portugal and Canada (5). Also, all the countries in the Organization for Economic Cooperation and Development (OECD), have the problem of unequal distribution of practitioners (13). Analysis of health workforce trends in Iran shows significant growth in the number over the past 30 years (14) and various patterns of equality. Although the number of health workforces increased by policies like growth in the number of universities (15), unfair distribution is seen $(16,17)$. In a study by Abbasi, Gini coefficient for nurses decreased, hospital beds remained constant and physicians increased during 2000-2008 (18). Also, a study of recruitment licensed physicians' distribution during 2005 - 2009 done by the Iranian Ministry of Health (IMOH), showed equitable distribution in Iran (5). In 2011, hemodialysis bed distribution was studied, and revealed equal status in connection with population needs in Iranian provinces, based on Gini coefficient. However, unequal distribution of nephrologists was reported (19). Inequalities in distribution of health inputs like hospital beds, nurses, and physicians etc. have been studied but evidence regarding maternal and child health related workforces is scarce. According to following millennium development goals (MDGs) in reducing the maternal mortality rate and increasing child health, special attention to relative health workforces is required. In this study, we aimed to show trends of distribution inequality in maternal and child health related workforces in relation with population needs, and calculate redistributive numbers based on Robin Hood index.

\section{Material and Methods}

This was a cross-sectional study in which inequality indices (Gini and Robin Hood) of health human resource distribution in Iran were calculated during 2010-2012. Data about the number of general physicians (GPs), midwives, gynecologists and pediatricians who work in the public (governmental) sector were obtained from the human resource office and the treatment deputy of the Iran health ministry report related to 2010 - 2012. Also, demographic statistics were obtained from the Statistical Center of Iran reported in 2012. To access data from the Ministry of Health (MOH) and the Statistical Center of Iran (SCI), researchers with an introduction letter referred to these organizations, and available data was recorded to an extraction data form, designed in the basis of study goals. In this study, we computed Human Resource per 10,000 Population Ratio (HRPR) as an indicator of human resource availability in each province and need adjusted index (NAI). So HRPR, according to the number of GPs, gynecologists, pediatricians, midwives, and population of each province was computed. To calculate NAI initially, in accordance with previous studies $(20,21)$, two variables including crude mortality rate (CMR) per 10,000 population and crude birth rate (CBR) per 10,000 population were used as indicators of population needs. Then, by dividing HRPR by CMR and CBR, need adjusted index for mortality (NAIM) and need adjusted index for birth (NAIB) was calculated. Then Gini coefficient and Lorenz curve of maternal health-related workforce in relationship with the province population and needs were calculated. The Gini coefficient is a measurement unit of statistical dispersion, usually used to measure the inequality in the distribution of income or wealth in a population. This index is defined as the ratio and has a value between zero and one. The Gini coefficient between 0.2 to 0.35 shows the relative balanced distribution, between 0.35 to 0.5 shows the distribution is relatively unequal and the index between 0.5 to 0.7 means the distribution is very unequal (22). Lorenz curve is as an important indicator for social inequalities in general. On the Lorenz curve, the vertical axis represents the cumulative percentage of income and the horizontal axis represents the cumulative percentage of the population. In the case of "uniform distribution of wealth among members of society", Lorenz curve distribution line shows same income in every person. In a situation in which all the wealth of one person and the rest of society does not have the assets or income, Lorenz curve becomes a "totally unequal distribution line" (22). In a case of inequality, the Robin Hood index was calculated to show how human health resources should be redistributed in the country. The Robin Hood index is associated with Lorenz curve. It is used to the better-known inequality measure of the Gini coefficient in relation to the Lorenz curve. The value of the Robin Hood index approximates the share of total number of human resources that needs to be reallocated. It guides human resource shift from rich provinces to the poor provinces to achieve equality. Its range is from 0 (perfect equality) to 100 (complete inequality) (22). So, in order to calculate the Robin Hood index, "Lorenz curve" was also drawn. For calculation, DAD software version 4.6 was used.

\section{Results}

Results showed that the ratio of general practitioners, midwives, pediatricians and gynecologists per 10,000 population in the year 2010 was $1.95,2.21,0.177$ and 0.218 , and in the year 2011 was 2.07, 2.2, 0.171 and 0.185. This ratio in the year 2012 raised to $2.05,2.24,0.208$ and 0.147 respectively. Table 1 displays the distribution of health-related workforces in the provinces of Iran during 2010-1012. This ratio was different within provinces and 
became different in the period of study. The highest ratio of general practitioners and midwives was in Chaharmahal Bakhtiari province, with a rate of 7.63 and 4.59 per 10,000 population. The highest ratio of pediatricians and gynecologists was in Yazd province $(0.74$ per 10,000) and Ilam province $(0.81$ per 10,000), respectively (Table 1$)$. Table 2 shows the Robin Hood index and Gini coefficient in terms of population, NAIM and NAIB, during the years 2010-2012. Gini coefficient was variable in the period of this study and demonstrated various trends in increasing and decreasing. Highest and lowest value of Gini coefficient was related to Gini coefficient of gynecologists in terms of NAIB in 2011 and in terms of population in 2012. This coefficient for GPs and pediatricians decreased, and for midwives increased during 2010-2012. Noticeable increase was observed for gynecologists in 2010 and 2011 and then it decreased in 2012. Highest value of Gini coefficient of GPs was based on NAIB in 2010, for midwives based on NAIB in 2011, and for gynecologists and pediatricians in terms of NAIB in 2010 and 2011 respectively. Likewise, the Robin Hood index had variable amounts, highest and lowest of this index was for gynecologists in accordance with population in 2011 and 2012 (34.7\% and 10.2\%), which was equal with the relocation of 476 and 113 specialists respectively. Highest amount of reallocation in GPs was 2,430 practitioners in 2010, for midwives 2,303 persons in 2012, for pediatricians 280 specialists in 2010 and for gynecologists was 460 specialists in 2011. All of them were in terms of NAIB. For achieving equality within provinces, the number of transferable health workforces was more than 1 person per 10 health workforces. This number was decreased in GPs, pediatricians and gynecologists and it was constant for midwives in the period of this study (Table 3).

Table 1. Distribution of health-related workforces in the provinces of Iran, years 2010-2012

\begin{tabular}{|c|c|c|c|c|c|c|c|c|c|c|c|c|}
\hline Index & \multicolumn{3}{|c|}{ HRPR for midwives } & \multicolumn{3}{|c|}{$\begin{array}{l}\text { HRPR for } \\
\text { Gynecologists }\end{array}$} & \multicolumn{3}{|c|}{$\begin{array}{l}\text { HRPR for } \\
\text { pediatricians }\end{array}$} & \multicolumn{3}{|c|}{ HRPR for GPs } \\
\hline Year & 2010 & 2011 & 2012 & 2010 & 2011 & 2012 & 2010 & 2011 & 2012 & 2010 & 2011 & 2012 \\
\hline East Azarbayjan & 1.93 & 2.39 & 2.63 & 0.38 & $0.04^{*}$ & 0.13 & 0.22 & $0.09 *$ & 0.17 & 2.74 & 3.45 & 2.14 \\
\hline West Azarbayjan & 1.84 & 2.53 & 2.62 & 0.22 & 0.09 & 0.19 & 0.15 & 0.17 & 0.19 & 1.95 & 3.55 & 2.17 \\
\hline Ardebil & 1.94 & 2.7 & 2.59 & 0.21 & 0.08 & 0.14 & 0.15 & 0.18 & 0.18 & 2.63 & 3.72 & 1.85 \\
\hline Isfahan & 2.0 & 1.87 & 2.04 & 0.12 & 0.06 & 0.15 & 0.18 & 0.22 & 0.23 & 1.92 & 4.09 & 2.17 \\
\hline Alborz & N/A & $1.15^{*}$ & 1.11 & $\mathrm{~N} / \mathrm{A}$ & $0.04^{*}$ & 0.11 & $\mathrm{~N} / \mathrm{A}$ & $0.09^{*}$ & $0.09^{*}$ & N/A & 1.71 & $0.88^{*}$ \\
\hline Ilam & $3.74^{* *}$ & 2.31 & 2.87 & 0.11 & $0.81^{* *}$ & 0.14 & 0.2 & 0.27 & 0.29 & 2.86 & 4.36 & 2.62 \\
\hline Bushehr & 3.11 & 2.92 & 2.86 & 0.23 & 0.08 & 0.15 & 0.15 & 0.19 & 0.21 & 3.13 & 4.6 & 2.45 \\
\hline Tehran & 1.3 & 1.24 & $1.0^{*}$ & N/A & 0.28 & 0.15 & N/A & 0.17 & 0.25 & $0.97^{*}$ & $1.21^{*}$ & 1.13 \\
\hline $\begin{array}{l}\text { Chaharmahal } \\
\text { Bakhtiari }\end{array}$ & 3.01 & $4.37^{* *}$ & $4.59^{* *}$ & $0.1^{*}$ & 0.05 & 0.18 & 0.11 & 0.24 & 0.25 & $6.14^{* *}$ & $7.63^{* *}$ & $5.19^{* *}$ \\
\hline South Khorasan & 2.65 & 1.6 & 1.75 & 0.15 & 0.06 & 0.14 & 0.25 & 0.27 & 0.27 & 1.81 & 4.23 & 2.26 \\
\hline Razavi Khorasan & 2.17 & 2.19 & 2.33 & 0.45 & 0.12 & 0.12 & 0.38 & 0.15 & 0.16 & 1.38 & 3.25 & 1.77 \\
\hline North Khorasan & 2.8 & 3.03 & 3.03 & 0.2 & 0.22 & $0.08^{*}$ & 0.17 & 0.12 & 0.13 & 1.1 & 3.08 & 2.29 \\
\hline Khuzestan & 2.41 & 2.52 & 2.49 & 0.12 & 0.05 & 0.11 & 0.13 & 0.14 & 0.16 & 2.05 & 2.56 & 1.9 \\
\hline Zanjan & 2.41 & 2.22 & 2.5 & 0.26 & $0.04^{*}$ & 0.22 & 0.29 & 0.3 & 0.31 & 2.5 & 5.02 & 2.93 \\
\hline Semnan & 3.29 & 3.16 & 3.41 & 0.29 & 0.69 & $0.43^{* *}$ & 0.47 & $0.48^{* *}$ & $0.6^{*}$ & 3.19 & 6.68 & 2.85 \\
\hline Sistan Baluchestan & 2.42 & 1.69 & 1.87 & $0.1^{*}$ & 0.07 & 0.1 & $0.09^{*}$ & 0.11 & 0.11 & 2.06 & 3.11 & 2.1 \\
\hline Fars & 2.52 & 1.95 & 2.05 & 0.4 & 0.4 & $0.08^{*}$ & 0.14 & 0.14 & 0.2 & N/A & 3.53 & 2.11 \\
\hline Qazvin & 1.87 & 1.36 & 1.48 & 0.29 & 0.15 & 0.13 & 0.31 & 0.24 & 0.24 & 2.26 & 3.38 & 1.91 \\
\hline Qom & 1.2 & 1.83 & 1.91 & 0.22 & 0.12 & 0.16 & 0.17 & 0.12 & 0.29 & 1.12 & 2.92 & 1.13 \\
\hline Kordestan & 3.08 & 1.96 & 1.91 & 0.16 & 0.2 & 0.13 & 0.18 & 0.16 & 0.18 & 2.41 & 3.03 & 0.185 \\
\hline Kerman & 2.3 & 2.8 & 2.46 & $0.1^{*}$ & 0.1 & 0.12 & $0.09^{*}$ & $0.09^{*}$ & 0.16 & 2.14 & 3.91 & 2.44 \\
\hline Kermanshah & 3.34 & 2.19 & 2.47 & 0.23 & 0.23 & 0.15 & 0.16 & 0.16 & 0.15 & 2.19 & 3.56 & 2.16 \\
\hline Kohgiluyeh & 3.1 & 2.6 & 2.95 & 0.19 & 0.75 & 0.26 & 0.2 & 0.24 & 0.32 & 5.58 & 5.43 & 3.19 \\
\hline Golestan & $1.13^{*}$ & 3.05 & 3.16 & 0.26 & 0.21 & 0.16 & 0.26 & 0.25 & 0.21 & 2.17 & 4.21 & 2.62 \\
\hline Gilan & 3.72 & 3.22 & 3.34 & 0.58 & 0.26 & 0.19 & 0.32 & 0.21 & 0.22 & 2.89 & 4.55 & 2.93 \\
\hline Lorestan & 3.08 & 2.82 & 3.14 & 0.2 & 0.2 & 0.18 & 0.16 & 0.15 & 0.18 & 2.51 & 3.9 & 2.71 \\
\hline Mazandaran & 3.28 & 3.56 & 3.52 & 0.3 & 0.3 & 021 & 0.28 & 0.28 & 0.3 & 3.19 & 5.75 & 2.6 \\
\hline Markazi & 1.25 & 2.55 & 2.54 & 0.26 & 0.26 & 0.17 & 0.22 & 0.22 & 0.19 & 2.38 & 3.47 & 2.25 \\
\hline Hormozgan & 2.2 & 2.12 & 2.17 & 0.37 & 0.15 & 0.13 & 0.29 & 0.12 & 0.2 & 2.46 & 3.76 & 2.56 \\
\hline Hamedan & 2.51 & 2.74 & 2.78 & 0.17 & 0.16 & 0.17 & 0.25 & 0.18 & 0.24 & 3.08 & 4.88 & 2.7 \\
\hline Yazd & 2.37 & 2.59 & 2.54 & $0.69^{* *}$ & 0.22 & 0.27 & $0.74^{* *}$ & 0.25 & 0.37 & 2.62 & 6.72 & 3.27 \\
\hline
\end{tabular}

HRPR: Human resource per population ratio; GPs: General physicians; * shows lowest ratio; ${ }^{*}$ shows highest ratio; N/A: Data was not available 
Table 2. Robin Hood index and Gini coefficient in terms of Population, NAIM and NAIB in provinces of Iran, years 2010-2012

\begin{tabular}{|l|l|l|l|l|l|l|l|}
\hline \multicolumn{2}{|l}{ Year } & \multicolumn{2}{l}{2010} & 2011 & & 2012 \\
\hline Index & Robin hood & Gini & Robin Hood & Gini & Robin Hood & Gini \\
\hline \multirow{3}{*}{ General Practitioners } & population & $16.1 \%$ & 0.23 & $13.2 \%$ & 0.187 & $11.9 \%$ & 0.173 \\
\cline { 2 - 9 } & NAIM $^{*}$ & $15.9 \%$ & 0.219 & $13 \%$ & 0.176 & $11 \%$ & 0.16 \\
\cline { 2 - 9 } & NAIB $^{* *}$ & $17 \%$ & 0.231 & $14.2 \%$ & 0.201 & $13.1 \%$ & 0.183 \\
\hline \multirow{3}{*}{ Midwives } & population & $12.5 \%$ & 0.176 & $12.6 \%$ & 0.176 & $13.5 \%$ & 0.19 \\
\cline { 2 - 8 } & NAIM & $11.9 \%$ & 0.17 & $11.8 \%$ & 0.168 & $12 \%$ & 0.172 \\
\cline { 2 - 8 } & NAIB & $12.8 \%$ & 0.178 & $13 \%$ & 0.177 & $13.7 \%$ & 0.193 \\
\hline Pediatricians & population & $19.2 \%$ & 0.259 & $12.7 \%$ & 0.185 & $11.4 \%$ & 0.159 \\
\cline { 2 - 8 } & NAIM & $18.2 \%$ & 0.239 & $13.7 \%$ & 0.192 & $13.3 \%$ & 0.177 \\
\cline { 2 - 8 } & NAIB & $21.5 \%$ & 0.298 & $18.3 \%$ & 0.247 & $17.4 \%$ & 0.232 \\
\hline \multirow{3}{*}{ Gynecologists } & population & $22.6 \%$ & 0.297 & $29.8 \%$ & 0.39 & $10.2 \%$ & 0.152 \\
\cline { 2 - 8 } & NAIM & $20.4 \%$ & 0.272 & $30 \%$ & 0.391 & $11.3 \%$ & 0.161 \\
\cline { 2 - 8 } & NAIB & $25.4 \%$ & 0.332 & $34.7 \%$ & 0.442 & $15.7 \%$ & 0.216 \\
\hline
\end{tabular}

*NAIB: Need adjusted index for birth; **NAIM: Need adjusted index for mortality.

Table 3. Number of transferable worker per 10 health workforces

\begin{tabular}{|l|l|l|l|l|l|l|}
\hline 2010 & NAIB & NAIM & population & NAIB & NAIM & population \\
\hline Index & 1.7 & 1.6 & 1.6 & 1.3 & 1.1 & 1.2 \\
\hline General practitioners & 1.3 & 1.2 & 1.25 & 1.4 & 1.2 & 1.4 \\
\hline Midwives & 2.16 & 1.8 & 1.9 & 1.7 & 1.3 & 1.14 \\
\hline Pediatricians & 3.8 & 3.1 & 3.4 & 1.6 & 1.1 & 1.0 \\
\hline Gynecologists & & & &
\end{tabular}

*NAIB: Need adjusted index for birth; **NAIM: Need adjusted index for mortality.

\section{Discussion}

The current study assessed geographic need and access distribution indices of general practitioners (GPs), midwives, pediatricians and gynecologists in the public sector of Iran during 2010-2012. Distribution of health workforces according to population and need (birth and mortality) was measured. The number of these health workforces per 10,000 population was increased for GPs and pediatricians, decreased for gynecologists and constant for midwives, during study period. Although findings showed that GPs distribution in terms of population, NAIB and NAIM improved during the study period; based on the Robin Hood index, redistribution of GPs can help in reaching a more equitable situation. GPs distribution was less equitable based on birth, and in turn, more GPs should be redistributed in Iran provinces. Tehran, the capital of Iran and Alborz are the most deprived provinces based on GP allocation. It may be because the GPs of these provinces are working more in the private sector. It is also important to note that in this study, we did not analyze the inequality between the cities in a province. Distribution of GPs in Turkey is slightly better than Iran in which Gini coefficient improved significantly from 0.24 to 0.12 between 2002 and 2012 (23). A 2006 study by Theodorakis also showed that distribution of GPs has improved between the years 2000 and2004 in Albania (21). However, Tanihara in 2011 showed that increasing the number of physicians in Japan did not lead to a more equitable allocation (24). Findings about midwives' distribution showed a slightly worsening trend in terms of population, NAIB and NAIM. Robin Hood index also showed more redistribution need for better equality in terms of NAIB. Tehran and Alborz provinces are the most deprived provinces based on midwives' allocation like GPs and it may be because of private sector preference in these provinces. Chaharmahal Bakhtiari province - with traditional culture and having nomads as a major population - is the most sparse province in terms of midwives' allocation. So, midwives' demand in this province is high. Gökylldı showed that people living in mountains and plains like nomads, prefer traditional health practices such as midwifery for their maternal health (25), which can explain our results. Although Izutsu showed improvement in midwives' distribution in Japan from 2000 to 2010 (26), distribution of midwives worsened from 2006 to 2008 in this country which was similar to our results. Distribution of gynecologists had different trends. First it became worse and then improved markedly. The Iran Ministry of health (IMOH), in a national plan in 2011, required last-year gynecologic residents to spend one month in deprived provinces according to national allocative needs. It could be the reason of equity improvement in the last year of study. Robin Hood index also showed reduction in redistribution need for gynecologists at the end of study. Also, we should note that decrease in the number of gynecologists had no negative effect on distribution that 
showed good policy making of IMOH. Karyani, in his study also showed increasing and decreasing trends in Gini coefficient of gynecologists during 2008-2013 (27) that is similar to our results. Our results showed an improving trend in pediatricians' distribution. Although equity improved, the Robin Hood index showed the possibility to receive better equity condition - especially in terms of birth need - by redistributing pediatricians. Kerman and Sistan Baluchestan were the most deprived provinces in terms of pediatricians, in 2010 and 2011. On the other hand, Sistan Baluchestan had the highest mortality rate of infants under 1 year and children under 5 years (28) in the period of study, and special attention is required. Semnan and Yazd provinces are the richest. Investigating Gini coefficient trend in our study, showed that Gini coefficient had decreased, but most of this reduction is due to increase in pediatricians in developing provinces, and deprived provinces still have serious problems in accessing these types of health experts. Kazemi, in his study, showed that industrial and tourist centers like Semnan had more growth in the number of pediatricians, and border provinces like Sistan Baluchestan had less growth (17). For achieving perfect equality, we should see all factors. Matsumoto, in 2010, showed that by increasing the number of physicians and health workforces in the USA and Japan, there is no evidence of equal distribution yet (29). It means that other factors than number of health workforces, may affect equality condition. This study had some limitations. Statistics about the number of GPs, gynecologists and pediatricians were not available in 2010 in some provinces such as Fars and Tehran, which forced us to remove these provinces. We didn't study private sector and distribution status within a province that could make more clear aspects of distribution and equity.

\section{Conclusions}

The reduction or increase in human resources throughout the country does not lead to a better or worse human resource distribution in the country, unless equal distribution is intended. Health workforce distribution had various trends in Iran. Although the resultant of these trends was better condition there was no evidence regarding special attention to deprived provinces. Gini coefficient had decreased, but most of this reduction is due to increase in health workforce in developing provinces, and deprived provinces still have serious problems for accessing posture. The health system could achieve better equality by considering deprived provinces and using Robin Hood index together. This policy could improve equality conditions.

\section{Acknowledgments:}

This study was part of a Master thesis number 91-6410, financially supported by Shiraz University of Medical Sciences and approved by the University Research Council in January 8, 2013.

\section{Conflict of Interest:}

There is no conflict of interest to be declared.

\section{Authors' contributions:}

All authors contributed to this project and article equally. All authors read and approved the final manuscript.

\section{References:}

1) Nolan CT, Garavan TN. Human resource development in SMEs: a systematic review of the literature. International Journal of Management Reviews. 2016; 18(1): 85-107. doi: 10.1111/ijmr.12062.

2) Olsen ØE, Ndeki S, Norheim OF. Human resources for emergency obstetric care in northern Tanzania: distribution of quantity or quality? Hum Resour Health. 2005; 3: 5. doi: 10.1186/1478-4491-3-5. PMID: 16053519, PMCID: PMC1199615.

3) Dal Poz MR, Sepulveda HR, Couto MHC, Godue C, Padilla M, Cameron R, et al. Assessment of human resources for health programme implementation in 15 Latin American and Caribbean countries. Human resources for health. 2015; 13: 24. doi: 10.1186/s12960-015-0016-4.

4) Faqir M, Zainullah P, Tappis H, Mungia J, Currie S, Kim YM. Availability and distribution of human resources for provision of comprehensive emergency obstetric and newborn care in Afghanistan: a crosssectional study. Confl Health. 2015; 9: 9. doi: 10.1186/s13031-015-0037-6. PMID: 25825592, PMCID: PMC4378548.

5) Mobaraki H, Hassani A, Kashkalani T, Khalilnejad R, Chimeh EE. Equality in Distribution of Human Resources: the Case of Iran's Ministry of Health and Medical Education. Iran J Public Health. 2013; 42(Supple1): 161-5. PMID: 23865035, PMCID: PMC3712591.

6) Jin J, Wang J, Ma X, Wang Y, Li R. Equality of Medical Health Resource Allocation in China Based on the Gini Coefficient Method. Iran J Public Health. 2015; 44(4): 445-57. PMID: 26056663, PMCID: PMC4441957. 
7) Organization WH. The world health report 2003: shaping the future: World Health Organization; 2003.

8) Yuan B, Malqvist M, Trygg N, Qian X, Ng N, Thomsen S. What interventions are effective on reducing inequalities in maternal and child health in low- and middle-income settings? A systematic review. BMC public health. 2014; 14: 634. doi: 10.1186/1471-2458-14-634.

9) Chen M, Palmer AJ, Si L. Assessing equity in benefit distribution of government health subsidy in 2012 across East China: benefit incidence analysis. Int J Equity Health. 2016; 15: 15. doi: 10.1186/s12939-0160306-z.

10) Saito E, Gilmour S, Yoneoka D, Gautam GS, Rahman MM, Shrestha PK, et al. Inequality and inequity in healthcare utilization in urban Nepal: a cross-sectional observational study. Health policy and planning. 2016; 31(7): 817-24. doi: 10.1093/heapol/czv137.

11) Zhou $\mathrm{K}$, Zhang $\mathrm{X}$, Ding $\mathrm{Y}$, Wang $\mathrm{D}, \mathrm{Lu} \mathrm{Z}, \mathrm{Yu}$ M. Inequality trends of health workforce in different stages of medical system reform (1985-2011) in China. Hum Resour Health. 2015; 13: 94. doi: 10.1186/s12960015-0089-0. PMID: 26645960, PMCID: PMC4673776.

12) Anyangwe SC, Mtonga $C$. Inequities in the global health workforce: the greatest impediment to health in sub-Saharan Africa. Int J Environ Res Public Healt. 2007; 4(2): 93-100. PMID: 17617671, PMCID: PMC3728573.

13) Hann M, Gravelle H. The maldistribution of general practitioners in England and Wales: 1974-2003. Br J Gen Pract. 2004; 54(509): 894-8. PMID: 15588532, PMCID: PMC1326105.

14) Tabatabai S, Ziaee AM, Simforoosh N. Evidence-based health human resources planning and medical professionals' education in Iran. BMC Health Services Research. 2014; 14(Suppl 2): P123. doi: 10.1186/1472-6963-14-S2-P123. PMCID: PMC4123135.

15) Ravaghi H, Taati E, Abdi Z, Meshkini A, Sarvari S. Factors influencing the geographic distribution of physicians in Iran: a qualitative study. Rural and Remote Health. 2015; 15(1): 2967.

16) Kiadaliri AA, Najafi B, Haghparast Bidgoli H. Geographic distribution of need and access to health care in rural population: an ecological study in Iran. Int J Equity Health. 2011; 10: 39. doi: 10.1186/1475-9276-10-39.

17) Kazemi Karyani A, Kazemi Z, Shaahmadi F, Arefi Z, Ghazanfari S. Determining Inequality and Trend of Geographic Accessibility to Pediatricians in Iran: 2007-2013. International Journal of Pediatrics. 2015; 3(21): 51-8. doi: 10.22038/ijp.2015.3945.

18) Abbasi M, Hasoumi M, Mohamadi E, Asadi H. Analysis of the relationship between distributions of health sector inputs and health outcomes in Iran; using Gini coefficient. Bioethics Journal. 2014; 4(12): 65-79.

19) Omrani Khoo H, Lotfi F, Safari H, Zargar Balaye Jame S, Moghri J, Shafii M. Equity in Distribution of Health Care Resources; Assessment of Need and Access, Using Three Practical Indicators. Iran J public health. 2013; 42(11): 1299-308. PMID: 26171343, PMCID: PMC4499072.

20) Wilkinson D. Inequitable distribution of general practitioners in Australia: analysis by state and territory using census data. Aust J Rural Health. 2000; 8(2): 87-93. doi: 10.1046/j.1440-1584.2000.00255.x. PMID: 11111425 .

21) Theodorakis PN, Mantzavinis GD, Rrumbullaku L, Lionis C, Trell E. Measuring health inequalities in Albania: a focus on the distribution of general practitioners. Hum Resour Health. 2006; 4: 5. doi: 10.1186/1478-4491-4-5. PMID: 16504028, PMCID: PMC1395320.

22) Kakwani NC. Applications of Lorenz curves in economic analysis. Econometrica. 1977; 45(3): 719-28.

23) Uner S, Yardim M, Mollahaliloğlu S. The change of the distribution of health human resource imbalance in 2002-2012: the case of Turkey. The European Journal of Public Health. 2015; 25(suppl 3): 105-6.

24) Tanihara S, Kobayashi Y, Une H, Kawachi I. Urbanization and physician maldistribution: a longitudinal study in Japan. BMC health services research. 2011; 11: 260. doi: 10.1186/1472-6963-11-260.

25) Gökyıldız Ş, Alan S, Öztürk M, Şenesen RO. Traditional health practices in mountain, plain and seaside regions of Adana in Turkey: Maternal and infant health. Lokman Hekim Journal. 2013; 3(3): 21-9.

26) Izutsu M, Suzuki E, Izutsu Y, Doi H. Trends in geographic distribution of nursing staff in Japan from 2000 to 2010: a multilevel analysis. Acta Med Okayama. 2014; 68(2): 101-10. PMID: 24743785.

27) Kazemi Karyani A, Azami SR, Rezaei S, Shaahmadi F, Ghazanfari S. Geographical distribution of gynecologists and midwives in Kermanshah province (2008-2013). Journal of Kermanshah University of Medical Sciences. 2015; 19(5): 294-302.

28) Rafiei E, Hashemi Nazari SS, Mehrabi Y. Indirect Estimation of Infant and Child Mortality Rates in Iran: Using 2006 and 2011 Census Data. J Mazandaran Univ Med Sci. 2015; 24(122): 32-43.

29) Matsumoto M, Inoue K, Bowman R, Noguchi S, Toyokawa S, Kajii E. Geographical distributions of physicians in Japan and US: Impact of healthcare system on physician dispersal pattern. Health Policy. 2010; 96(3): 255-61. doi: 10.1016/j.healthpol.2010.02.012. PMID: 20236722. 